\title{
Silent Myocardial Infarction by ECG
}

\section{Finding}

National Cancer Institute

\section{Source}

National Cancer Institute. Silent Myocardial Infarction by ECG Finding. NCI Thesaurus.

Code C101598.

An electrocardiographic finding that a myocardial infarction has occurred concurrently with the absence of clinical symptoms. 